\title{
Etidronate, calcium, or both did not reduce fracture rates in patients with asthma receiving glucocorticoid treatment
}

Campbell IA, Douglas JG, Francis RM, et al. Five year study of etidronate and/or calcium as prevention and treatment for osteoporosis and fractures in patients with asthma receiving long term oral and/or inhaled glucocorticoids. Thorax 2004;59:761-8.

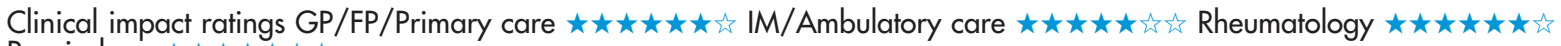

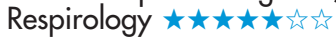

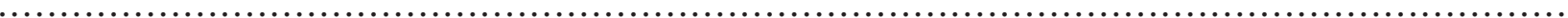

In patients with asthma receiving long term glucocorticoid treatment, does etidronate, calcium, or both reduce fracture rates?

METHODS

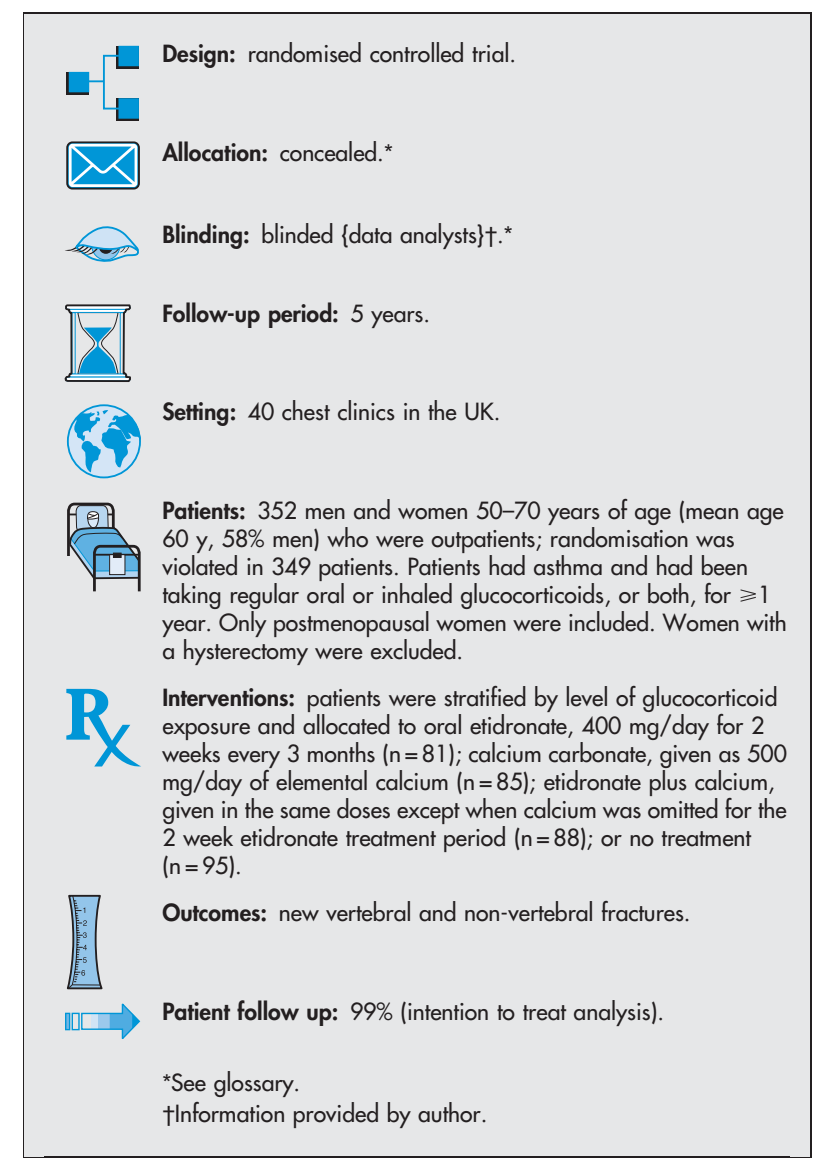

\section{MAIN RESULTS}

The groups did not differ for mortality $(10 \%, 24 \%, 16 \%$, and $16 \%$ in the etidronate only, calcium only, etidronate plus calcium, and no treatment groups, respectively); symptomatic fractures $(6 \%, 8 \%, 10 \%$, and $7 \%$, respectively); or symptomatic fractures, semi quantitative vertebral fractures, or both $(16 \%, 18 \%, 16 \%$, and $20 \%$, respectively). Groups receiving etidronate compared with groups not receiving etidronate, and groups receiving calcium compared with groups not receiving calcium, did not differ for rates of any fractures, respectively (table).

\section{CONCLUSION}

In patients with asthma receiving long term glucocorticoid treatment, etidronate and calcium used alone or combined did not reduce fracture rates.

For correspondence: Dr I A Campbell, Llandough Hospital, Penarth, UK ian.campbell@cardiffandvale.wales.nhs.uk

Sources of funding: Allen and Hanburys, and Glaxo.
Abstract and commentary also appear in ACP Journal Club.

Etidonate (Et) containing regimens or calcium $(\mathrm{Ca})$ containing regimens to prevent any fracture in patients with asthma receiving long term glucocorticoid treatment ${ }^{\star}$

\begin{tabular}{|c|c|c|c|}
\hline Comparisons & $\begin{array}{l}\text { Event } \\
\text { rates }\end{array}$ & RRR (95\% Cl) & NNT \\
\hline $\begin{array}{l}\text { Et and } \mathrm{Et+Ca} v \mathrm{Ca} \text { and } \\
\text { no treatment } \\
\mathrm{Ca} \text { and } \mathrm{Et}+\mathrm{Ca} v \mathrm{Et} \text { and } \\
\text { no treatment }\end{array}$ & $\begin{array}{l}16 \% v \\
19 \% \\
17 \% v \\
18 \%\end{array}$ & $\begin{array}{l}15 \%(-33 \text { to } 46) \\
8 \%(-45 \text { to } 41)\end{array}$ & $\begin{array}{l}\text { Not } \\
\text { significant } \\
\text { Not } \\
\text { significant }\end{array}$ \\
\hline
\end{tabular}

*Abbreviations defined in glossary; RRR, NNT, and $\mathrm{Cl}$ calculated from data in article.

\section{Commentory}

ampbell et al studied the effects of etidronate (with and without calcium), calcium, or placebo on bone mineral density (BMD) and fractures in patients taking oral or inhaled glucocorticoids or both for asthma. Patients randomised to etidronate had a $5 \%$ increase in lumbar spine BMD. No difference between groups existed in hip BMD or fractures. Calcium, $500 \mathrm{mg} /$ day, did not have any additional benefit.

How does one interpret these results? Lack of statistical power may explain the negative findings because the study achieved only $50 \%$ of its recruitment target. Previous studies show that etidronate is effective at preventing bone loss in patients treated with glucocorticoids, and 1 trial of shorter duration showed a reduction in height loss and vertebral fracture. ${ }^{1}$ Perhaps the effect of etidronate was diminished because patients had other risk factors for fractures that were not assessed or treated, although levels of exercise did not differ between treatment groups. Alternatively, etidronate may not be potent enough for long term fracture prevention. The lack of an additional effect of calcium is not surprising; the dose was low, and the data for calcium and vitamin $D$ in glucocorticoid induced osteoporosis are not compelling.'

How can we apply findings from this study to the management of glucocorticoid induced osteoporosis? Until further long term studies of the newer bisphosphonates are completed, patients with low trauma fractures should be prescribed a bisphosphonate, risedronate or alendronate, regardless of BMD. ${ }^{1}$ Men and women taking oral or inhaled steroids at doses of $\geqslant 1000 \mu \mathrm{g} /$ day should have BMD testing. For patients with $\mathrm{T}$ scores $<-2.0$ to -1.5 , prescription of bisphosphonates should be considered.

What bisphosphonate should one use? Alendronate and risedronate are the only approved bisphosphonates in the US. In Canada and Europe, etidronate is also available. However, findings from this study by Campbell et al, and the lack of studies showing that etidronate decreases hip and non-spinal fractures in patients treated with steroids and in postmenopausal women, suggest that etidronate is not the best choice. Sophie A Jamal, MD, PhD St Michael's Hospital, University of Toronto Toronto, Ontario, Canada

1 Reid IR, Wu F. Glucocorticoid-induced osteoporosis. In: Cummings SR,

Cosman F, Jamal SA, eds. Osteoporosis: an evidence-based guide to prevention and management. Philadelphia: American College of Physicians, 2002:223-38. 